\title{
PENGARUH PELATIHAN, MOTIVASI, KOMPETENSI TERHADAP KINERJA SUMBER DAYA MANUSIA
}

\author{
Dr.E. Marno Nugroho MM \\ Fakultas Ekonomi Unissula Semarang \\ Email : marnonugroho@unissula.ac.id
}

\section{Renjana Paradifa}

Fakultas Ekonomi Unissula Semarang

Email : renjanaparadif@ymail.com

\begin{abstract}
ABSTRAK
Tujuan penelitian ini yaitu mendeskripsikan keterkaitan pelatihan,kompetensi, dan motivasi aktualisasi diri terhadap kinerja SDM serta meyusun model peningkatan kinerja SDM yang optimal. Variabel independen dalam penelitian yaitu pelatihan, kompetensi, dan motivasi aktualisasi diri.Variabel dependennya adalah kinerja SDM.Serta variabel interveningnya adalah kompetensi. Populasi dalam penelitian yaitu karyawan tetap yang terdapat di PDAM Tirta Kencana Kota Samarinda.Sampel dihitung memakai rumus slovin dan hasilnya 177 responden. Pengumpulan data dilakukan dengan observasi, dokumentasi, beberapa jurnal terdahulu, wawancara, dan kuesioner yang disebarkan langsung. Metode analisis yaitu deskriptif dan statistik. Hasil menunjukkan variabel pelatihan, kompetensi, dan motivasi berpengaruh positif terhadap kinerja SDM dan pelatihan berpengaruh secara tidak langsung terhadap kinerja SDM melalui variabel intervening kompetensi.
\end{abstract}

Kata kunci: Pelatihan, kompetensi, motivasi aktualisasi diri, kinerja sdm, dan variabel intervening. 


\section{PENDAHULUAN}

Globalisasi serta perubahan keadaan ekonomi menyebabkan tingginya kompetisi pada berbagai perusahaan sehingga mengharuskan perusahaan untuk meningkatkan kinerja perusahaan, terutama kinerja SDM nya.Untuk meningkatkan kinerja SDM ini salah satunya yaitu, perusahaan harus menerapkan pelatihan kepada SDM nya agar SDM yang diperusahaan tersebut terlatih didalam menjalankan pekerjaannya sehingga bisa meningkatkan produktifitas dan kinerja perusahaan.Memberikan pelatihan saja tidak cukup, perusahaan juga harus bisa merekrut serta mempertahankan SDM yang berkompeten, karena diharap bisa dengan mudah beradaptasi terhadap pekerjaan yang mereka terima.Sehingga bisa dengan mudah menyelesaikan pekerjaan tersebut.

Dalam hal peningkatan kinerja SDM, juga diperlukan motivasi dari SDM itu sendiri, karena tanpa adanya motivasi maka kinerja yang ada pada SDM tidak akan optimal. Penerapan pelatihan, kompetensi, serta motivasi ini sangat diperlukan di PDAM Tirta Kencana Kota Samarinda. Perusahaan daerah ini dirasa kinerjanya kurang optimal, dikarenakan cakupan pelayanan mereka sebesar 95,98\% belum mencapai target rencana pembangunan menengah nasional (2015-2019) sebesar 100\%. Cakupan pelayanan yang belum mencapai target ini, salah satunya disebabkan karena tingkat kehilangan air yang makin meningkat dari tahun sebelumnya yaitu sebesar $4,77 \%$, dikarenakan petugas operator yang kurang teliti dalam mencatat angka meter.

Bagaimana meningkatkan kinerja SDM yang tidak optimal menjadi kajian di PDAM TIRTA KENCANA KOTA SAMARINDA, dengan mengajukan beberapa untuk pertanyaan penelitiannya yaitu: 1). Pengaruh pelatihan terhadap kinerja SDM. 2). Pengaruh motivasi terhadap kinerja SDM. 3). Pengaruh kompetensi terhadap kinerja SDM. 4). Pengaruh pelatihan terhadap kinerja SDM melalui kompetensi sebagai variabel intervening.

Selanjutnya penelitian ini bertujuan : a). Mendeskripsikan keterkaitan pelatihan, kompetensi, dan motivasi terhadap kinerja SDM di PDAM TIRTA KENCANA KOTA SAMARINDA. b) Menyusun model alternatif peningkatkan kinerja SDM yang kurang optimal pada PDAM TIRTA KENCANA KOTA SAMARINDA. 


\section{TELAAH PUSTAKA}

\section{Kinerja SDM}

Afshan dkk. (2012) kinerja sebagai; "Pencapaian tugas spesifik yang diukur berdasarkan standar akurasi, kelengkapan, biaya dan kecepatan. Cascio (2006) Kinerja mengarah pada tingkat keberhasilan sebuah pekerjaan karyawan.Barry Cushway (2002) Kinerja adalah menilai bagaimana seseorang telah bekerja dibandingkan dengan target yang telah ditentukan". Menurut Veizal Rivai (2004) mengemukakan kinerja adalah: "merupakan perilaku yang nyata yang ditampilkan setiap orang sebagai prestasi kerja yang dihasilkan oleh karyawan sesuai dengan perannya dalam perusahaan".

\section{a. Faktor yang mempengaruhi}

Menurut Robert L. Mathis dan John H. Jackson (2001) faktor-faktor yang memengaruhi kinerja individu tenaga kerja, yaitu: kemampuan mereka, motivasi, dukungan yang diterima, keberadaan pekerjaan yang mereka lakukan, dan hubungan mereka dengan organisasi. Kemudian Menurut Gibson (1987) ada 3 faktor yang berpengaruh terhadap kinerja: Faktor individu: kemampuan, ketrampilan, latar belakang keluarga, pengalaman kerja, tingkat sosial dan demografi individu. Faktor psikologi :kepribadian,kepuasan kerja, motivasi, peran, persepsi, dan sikap,. Faktor organisasi : struktur, desain pekerjaan, kepemimpinan, sistem penghargaan. Faktor yang mempengaruhi kinerja karyawan meliputi kemampuan, motivasi, dan organisasi (Vroom, 1964; Pringle, 1982).

\section{b. Indikator Kinerja SDM}

Berupa kualitas, kuantitas, ketepatan waktu, efektivitas, dan kemandirian.

\section{Pelatihan}

Aguinis \& Kraiger, (2009) Pelatihan merupakan pendekatan sistematis yang berdampak peningkatan pengetahuan, keterampilan, dan sikap untuk meningkatkan kemampuan individu, tim, dan organisasi agar lebih efektif. (Jagero et al., 2012) Pelatihan merupakan cara yang digunakan untuk meningkatkan kemampuan, keterampilan, dan pengetahuan karyawan melalui pemberian informasi baru supaya mereka bisa menjalankan pekerjaan secara efisien. Anwar prabu mangkunegara (2000) mendefinisikan pelatihan merupakan "suatu proses pendidikan jangka pendek yang mempergunakan prosedur sistematis dan terorganisasi, pegawai non manajerial mempelajari pengetahuan dan 
keterampilan teknis dalam tujuan yang terbatas”. Abdus Sattar Niazi, (2011) Berdasarkan berbagai sudut pandang, pelatihan didefinisikan sebagai: "Kegiatan belajar resmi dan konstan dalam sebuah organisasi yang bertujuan untuk meningkatkan kinerja karyawan".

Indikator : 1). Materi yang dibutuhkan. 2). Metode yang Digunakan. 3). Kemampuan Instruktur Pelatihan. 4). Sarana atau Prinsip-Prinsip Pembelajaran. 5). Peserta Pelatihan. 6). Evaluasi Pelatihan

\section{Kompetensi}

Kompetensi merupakan perilaku seseorang mencakup pengetahuan, keterampilan, motif, nilai serta konsep diri sehingga bekerja lebih efektif, unggul, serta sukses daripada yang lain (Boyatzis, 1982, di Velayudhan, 2011; Dubois , 1983 dan 1993 di Mills, 2006; Palan, 2007; Kesler, 2011,). Kompetensi didefinisikan pengetahuan, keterampilan, dan sikap seorang professional dalam menjalankanpekerjaan..(Chapman, 1999).Kompetensi adalah ketrampilan dari seorang ahli.Sri lastanti (2005).

\section{Indikator Kompetensi}

Motivasi trainee, sifat pelatihan, konsep aktualisasi diri, peningkatan pengetahuan dan ketrampilan.

\section{Motivasi}

(Kumar et al, 2003) Motivasi sebagai proses yang merangsang seseorang untuk bertindak atas sesuatu yang mereka inginkan, terkait dengan kemauan untuk bekerja keras untuk tujuan organisasi, dirangsang oleh insentif, dan dianggap sebagai insentif jika dirasakan dapat membantu mereka mencapai Tujuan mereka, Phares dan Chaplin (1997) di James Y. Shah dan Wendi L. Gardner (2008), motivasi didefinisikan sebagai kekuatan di dalam diri kita yang mengaktifkan dan mengarahkan perilaku menuju tujuan daripada yang lain. (Hanafi, 2003) Motivasi sebagai sesuatu yang mendorong seseorang untuk bertindak cara tertentu, dan motivasi membuat individu memulai, menerapkan, dan memelihara aktivitas tersebut. Terry Mitchell (1982) mendefinisikan motivasi merupakan proses psikologis yang menyebabkan keinginan yang bertujuan mencapai sebuah tujuan.

\section{Indikator}

Kebutuhan fisiologis, rasa aman,sosial, penghargaan, aktualisasi diri. 


\section{Kerangka Pemikiran dan Pengembangan Hipotesis}

a Pengaruh Pelatihan Terhadap Kinerja SDM dan Pengaruh Pelatihan terhadap kinerja SDM melalui variabel intervening Kompetensi SDM.

Jackson et.al (2011) "Perusahaan-perusahaan yang memiliki daya saing tinggi menggunakan praktik-praktik pelatihan untuk meningkatkan kemampuan pekerja demi melaksanakan strategi bisnis perusahaan." Ini berarti setiap perusahaan perlu adanya pelatihan untuk meningkatkan kinerja karyawan. Jadi apabila pelatihan kepada SDM semakin sering maka semakin meningkat juga kompetensi dan kinerja SDM yang diberikan pelatihan.

Studi American Journal of Business and Management dari Subari Subari and Hanes Riady mengemukakan pelatihan memiliki berpengaruh positif pada kinerja serta kompetensi memiliki berpengaruh positif pada pelatihan. Penelitian Heri Sapari Kahpi dkk, (2017) Pelatihan berpengaruh positif terhadap kompetensi, Hipotesis yang diajukan:

\section{H1: Pelatihan berpengaruh positif terhadap kinerja SDM.}

H2: Pelatihan berpengaruh positif terhadap kinerja SDM melalui variabel intervening kompetensi SDM.

\section{b Pengaruh Kompetensi Terhadap Kinerja SDM}

Mohd noor \& dola (2009) "competency include the aptitude necessary to enhance basic abilities and to raise job performance to a higher level".Kompetensi merupakan bakat yang diperlukan untuk meningkatkan kemampuan dasar untuk meningkatkan kinerja ke tingkatan lebih tinggi.Jika semakin tinggi kompetensi SDM yang dimiliki maka semakin tinggi juga kinerja SDM yang berkompeten.

Kompetensi mempengaruhi kinerja mendukung teori yang ada bahwa kinerja dipengaruhi oleh kemampuan berupa kompetensi (Vroom, 1964; Boyatzis, 1982).Penelitian terdahulu Mardia Hi.Rahman hasil penelitian menyatakan bahwa kompetensi profesional memiliki pengaruh positif terhadap kinerja guru.Penelitian yang dilakukan oleh Ni Putu Darmayanti dkk,(2014) menunjukkan ada pengaruh dari kompetensi intelektual terhadap kinerja. Maka hipotesis yang diajukan adalah :

\section{H3: Kompetensi berpengaruh positif terhadap kinerja SDM.}

\section{c Pengaruh Motivasi Aktualisasi Diri Terhadap Kinerja SDM}


Abraham H. Maslow (1954) mengemukakan indikator motivasi, salah satunya yaitu Kebutuhan Aktualisasi diri, merupakan kebutuhan puncak. Individu bertindak bukan dari orang lain, tetapi dari diri sendiri. Menurut Hasibuan (2010), motivasi berperan penting bagi karyawan karena dengan motivasi kerja diharapkan individu karyawan mau bekerja keras dan antusias untuk mencapai produktivitas kerja yang tinggi.Motivasi mempersoalkan bagaimana mendorong gairah kerja bawahan agar mereka mau bekerja keras dengan memberikan semua kemampuan dan keterampilanya untuk mewujudkan tujuan perusahaan. Dengan adanya motivasi, maka terjadilah kemauan kerja dan dengan adanya kemauan untuk bekerja serta dengan adanya kerja sama, maka kinerja akan meningkat.

Penelitian sebelumnya terhadap motivasi dan kinerja karyawan yang dilakukan oleh Nawab et al. (2011), Javed et al. (2011), dan Kaymaz dkk. (2011) dimana motivasi berpengaruh signifikan terhadap kinerja karyawan. Penelitian dari Subari Subari dan Hanes Riady menyatakan bahwa motivasi memiliki efek positif terhadap kompetensi.Penelitian yang dilakukan oleh Heri Sapari Kahpi, dkk (2017) Motivasi berprestasi memiliki pengaruh positif dan signifikan terhadap kinerja pegawai.Maka hipotesis yang diajukan adalah : H4: Motivasi Aktualisasi Diri berpengaruh positif terhadap kinerja SDM

\section{METODE PENELITIAN}

Disain penelitian adalah rencana dan prosedur riset dikembangkan dari penentuan asumsi, mengoleksi data, menganalisis dan menginterprestasinya. Jenis penelitian ini adalah fundamental research atau basic research yang bertujuan untuk ikut berpartisipasi dalam pengembangan ilmu pengetahuan (Sekaran, 2006). Bila diurakan lagi desain penelitian ini adalah penelitian kuantitatif yaitu membangun teori dengan melakukan pengujian hubungan antar variabel. Variabel tersebut dapat diukur, dijelaskan sebagai instrument dengan analisis statistik yang relevan dapat dilakukan interprestasi. (Creswell, 2014).

Riset kuantitatif juga memiliki unsur: Pre-determined, Instrument based questions, tentang kelayakan data serta analisis dan dapat diintepretasikan secara statistik sehingga dapat menjawab hipotesis yang dibangun. Penelitian ini merupakan penelitian non-eksperimen sebab peneliti tidak memberikan perlakuan (kontrol) terhadap subyek penelitian. Penelitian non eksperimen dibedakan dalam hal penelitian kasus, penelitian kausal komparatif, penelitian korelasi, penelitian historis dan penelitian filosofis. Penelitian ini merupakan 
penelitian korelasi, karena bertujuan menguji korelasi atau pengaruh diantara beberapa variabel penelitian.

Model cross-sectional dipilih sehubungan penelitian ini merupakan penelitian satu waktu tertentu dengan banyak responden. Penelitian ini berbeda_dengan model penelitian dengan model longitudinal yang mempelajari berbagai tingkat pertumbuhan yang seiring dengan perkembangan subyek penelitian.

\section{Sumber Data}

a. Data Primer. Hasil kuesioner kepada Pegawa PDAM Kota Samarinda yang dikumpulan bulan Mei-Juli 2019

\section{b. Data Sekunder}

Laporan tahunan dan laporan evaluasi kinerja PDAM tirta kencana kota Samarinda (2017- 2018)

\section{Metode Pengumpulan Data}

Observasi dan Dokumentasi, dari objek terkait di PDAM Tirta Kencana Kota Samarinda. Demikan pula dengan menkaji berbagai jurnal-jurnal terdahulu yang memiliki kesamaan topik. Disamping hal tersebut peneliti juga menggunakan teknik wawancara langsung maupun tidak langsung kepada subjek yang terlibat. kuesioner yang dibagikan ke PDAM Tirta Kencana Kota Samarinda.

Populasi : Seluruh karyawan tetap di PDAM Tirta Kencana Kota Samarinda berjumlah 318 Orang. Sampel : 177 orang responden.

\section{Variabel}

Independen : Pelatihan $\left(\mathrm{X}_{1}\right)$, kompetensi $\left(\mathrm{X}_{2}\right)$, Motivasi $\left(\mathrm{X}_{3}\right)$ Intervening Kompetensi SDM (X2/Y2). Dependen Kinerja SDM (Y1)

\section{Analisis deskriptif}

Kriteria penilaian kinerja SDM sebagai variabel dependen dan pelatihan, kompetensi, dan motivasi sebeagai variabel independen menggunakan rentang sebesar 1,33

$$
\begin{gathered}
\text { Rentang Nilai }=\frac{\text { Nilai Tertinggi }- \text { Nilai Terendah }}{\text { Jumlah Kriteria }} \\
\frac{5-1}{3}=1,33
\end{gathered}
$$

Interpretasi nilai:

$1,00-2,33=$ Kategori Rendah

2,34 - 3,66 = KategoriSedang 
$3,67-5,00=$ KategoriTinggi.

\section{c. Analisis statistic}

\section{Uji validitas}

Membandingkan nilai $r$ hitung dengan $r$ tabel.

Jika : r hitung $>$ r tabel, valid

Jika : $r$ hitung $<\mathrm{r}$ tabel, tidak valid

\section{Uji Reliabilitas}

Jika nilaiCronbach Alpha $>0,6$, reliabel.

\section{Uji multikolinieritas}

Jika : Nilai toleransi diatas 0,1 dan Nilai VIF dibawah 10 , tidak terjadi multikolinieritas.

Jika : Nilai toleransi dibawah 0,1 dan Nilai VIF diatas 10 , terjadi multikolinieritas.

\section{Heterodastisitas}

Tidak terjadi heterodastisitas jika titik-titik scatterplot pada sumbu Y menyebar diatas maupun dibawah angka 0 .

\section{Normalitas}

Jika data menyebar di sekitar garis diagonal, model regresi memenuhi asumsi normalitas.

Jika data menyebar jauh dari garis diagonal, maka model regresi tidak memenuhi asumsi normalitas.

\section{Regresi berganda}

Persamaan regresi:

$\mathrm{Y}_{1}=\mathrm{a}+\beta_{1} \mathrm{X}_{1}+\beta_{2} \mathrm{X}_{2}+\beta_{3} \mathrm{X}_{3}+\mathrm{e}$

$\mathrm{Y}_{2 /} \mathrm{X}_{2}=\mathrm{a}+\beta_{1} \mathrm{X}_{1}+\mathrm{e}$

Dimana :

$$
\begin{array}{ll}
\mathrm{Y}_{1} & : \text { Kinerja SDM } \\
\mathrm{Y}_{2 / \mathrm{X} 2} & : \text { Kompetensi SDM } \\
\mathrm{X}_{1} & : \text { Pelatihan } \\
\mathrm{X}_{3} & : \text { Motivasi Aktualisasi Diri } \\
\mathrm{a} & : \text { Konstanta } \\
\beta \mathrm{i} & : \text { Koefisien regresi } \\
\mathrm{e} & : \text { Pengaruh lain }
\end{array}
$$




\section{Uji t}

Uji t membandingkan nilai thitung dengan nilai t tabel pada $\alpha=0.05$.

Pengujian pengaruh variabel bebas yaitu Pelatihan, kompetensi, motivasi aktualisasi diri terhadap variabel terikat Kinerja SDM.

Ho: $\mathrm{t}$ hitung $<\mathrm{t}$ tabel, variabel independen tidak berpengaruh terhadap variabel dependen.

Ha: $t$ hitung > t tabel, variabel independen berpengaruh terhadap variabel dependen.

\section{Uji t Intervening}

Uji t membandingkan nilai thitung dengan nilai t tabel pada $\alpha=0.05$.

Pengujian pengaruh tidak langsung variabel pelatihan terhadap kinerja SDM melalui variabel intervening Kompetensi.

Ho: thitung < t tabel, variabel bebas tidak berpengaruh terhadap variabel terikat.

Ha: $t$ hitung $>t$ tabel, variabel bebas berpengaruh terhadap variabel terikat.

\section{Uji Model}

Uji model membandingkan F hitung dengan F tabel pada $\alpha=0.05$.

Ho: $\mathrm{F}$ hitung < F tabel, variabel bebas tidak berpengaruh bersama-sama terhadap variabel terikat.

Ha: F hitung > F tabel, variabel bebas berpengaruh bersama-sama terhadap variabel terikat.

\section{Koefisien Determinasi $\left(R^{2}\right)$}

Melihat besarkontribusi variabel bebas terhadap variabel terikat.Jika $R^{2}$ mendekati 1 , maka besar kontribusi yang diberikan variabel bebas semakin besar.Secara umum $R^{2}$ berada diantara 0 dan 1 atau $0 \leq R^{2} \geq 1$.

\section{HASIL DAN PEMBAHASAN}

\section{Karakteristik Responden}

\section{Jenis kelamin}

Mayoritas karyawan PDAM Tirta Kencana Kota Samarinda yang dijadikan responden adalah pria yaitu sebesar 68,4 persen dari keseluruhan responden.Hal ini dikarenakan PDAM merupakan perusahaan yang membutuhkan banyak tenaga teknis lapangan.

\section{Usia}

Mayoritas karyawan PDAM Tirta Kencana Kota Samarinda yang dijadikan responden berusia antara 26-35 tahun, sebesar 55,4 persen dari keseluruhan responden. Karena pada usia 
tersebut termasuk dalam usia produktif dalam menjalankan pekerjaan yang membutuhkan mobilitas tinggi.

\section{Masa Kerja}

Mayoritas respondennya adalah karyawan dengan masa kerja diatas 5 tahun, yaitu sebesar 59,9 persen, dari keseluruhan responden.Karena karyawan berpengalaman diharap lebih mudah beradaptasi dalam pekerjaan yang diberikan oleh perusahaan.

\section{Pendidikan Terakhir}

Mayoritas karyawan PDAM Tirta Kencana Kota Samarindayang dijadikan responden berpendidikan perguruan tinggi sebanyak 116 orang atau sebesar 65,5 persen dari keseluruhan responden. Karena karyawan berkompeten berfikir lebih logis, sistematis, dan analitis dalam menjalankan pekerjaannya dibanding karyawan yang lulusan SMA.

\section{Uji Validitas dan Reliabilitas}

Tabel 4.1

Uji Validitas Data

\begin{tabular}{|c|c|c|c|c|c|}
\hline No & Variabel & Indikator & $\mathbf{r}$ hitung & $r$ tabel & Keterangan \\
\hline \multirow[t]{5}{*}{1} & Kinerja SDM & Kualitas & 0,733 & 0,1476 & Valid \\
\hline & & Kuantitas & 0,568 & 0,1476 & Valid \\
\hline & & Ketepatan waktu & 0,738 & 0,1476 & Valid \\
\hline & & Efektifitas & 0,522 & 0,1476 & Valid \\
\hline & & Kemandirian & 0,553 & 0,1476 & Valid \\
\hline \multirow[t]{6}{*}{2} & Pelatihan & $\begin{array}{l}\text { Materi yang } \\
\text { dibutuhkan }\end{array}$ & 0,764 & 0,1476 & Valid \\
\hline & & $\begin{array}{l}\text { Metode yang } \\
\text { digunakan }\end{array}$ & 0,661 & 0,1476 & Valid \\
\hline & & $\begin{array}{c}\text { Kemampuan instruktur } \\
\text { pelatihan }\end{array}$ & 0,473 & 0,1476 & Valid \\
\hline & & $\begin{array}{l}\text { Sarana atau prinsip- } \\
\text { prinsip pembelajaran }\end{array}$ & 0,479 & 0,1476 & Valid \\
\hline & & Peserta pelatihan & 0,673 & 0,1476 & Valid \\
\hline & & Evaluasi pelatihan & 0,593 & 0,1476 & Valid \\
\hline \multirow[t]{4}{*}{3} & Kompetensi & Motif (motive), & 0,665 & 0,1476 & Valid \\
\hline & & Sifat (traits) & 0,575 & 0,1476 & Valid \\
\hline & & $\begin{array}{c}\text { Konsep diri (self } \\
\text { concept) }\end{array}$ & 0,606 & 0,1476 & Valid \\
\hline & & $\begin{array}{l}\text { Pengetahuan } \\
\text { (knowledge) }\end{array}$ & 0,618 & 0,1476 & Valid \\
\hline
\end{tabular}




$\begin{array}{ccccc} & \text { Keterampilan (skill) } & 0,671 & 0,1476 & \text { Valid } \\ \text { Kebutuhan fisiologis } & 0,648 & 0,1476 & \text { Valid } \\ \text { Kebutuhan rasa aman } & 0,610 & 0,1476 & \text { Valid } \\ \text { Kebutuhan sosial } & 0,643 & 0,1476 & \text { Valid } \\ \text { Kebutuhan } & 0,647 & 0,1476 & \text { Valid } \\ \text { penghargaan } & & & \\ \text { Kebutuhan aktualisasi } & 0,668 & 0,1476 & \text { Valid } \\ \text { diri } & & & \end{array}$

nilai r hitung (Corrected Item-Total Correlation) variabel kinerja SDM, pelatihan, kompetensi, motivasi lebih dari r tabel Product Moment (> 0,1476) sehingga dapat disimpulkan seluruh pertanyaan dalam kuesioner dinyatakan valid.

Tabel 4.2

Uji Reliabilitas Data

\begin{tabular}{llll}
\hline No & Variabel & Alpha & Keterangan \\
\hline 1 & Kinerja SDM & 0,820 & Reliabel \\
2 & Pelatihan & 0,932 & Reliabel \\
3 & Kompetensi & 0,917 & Reliabel \\
4 & Motivasi & 0,853 & Reliabel \\
\hline
\end{tabular}

nilai koefisien reliabilitas Cronbach Alpha lebih dari 0,6 maka instrumen penelitian dinyatakan reliabel.

Tabel 4.3

Statistik Deskriptif Kinerja SDM

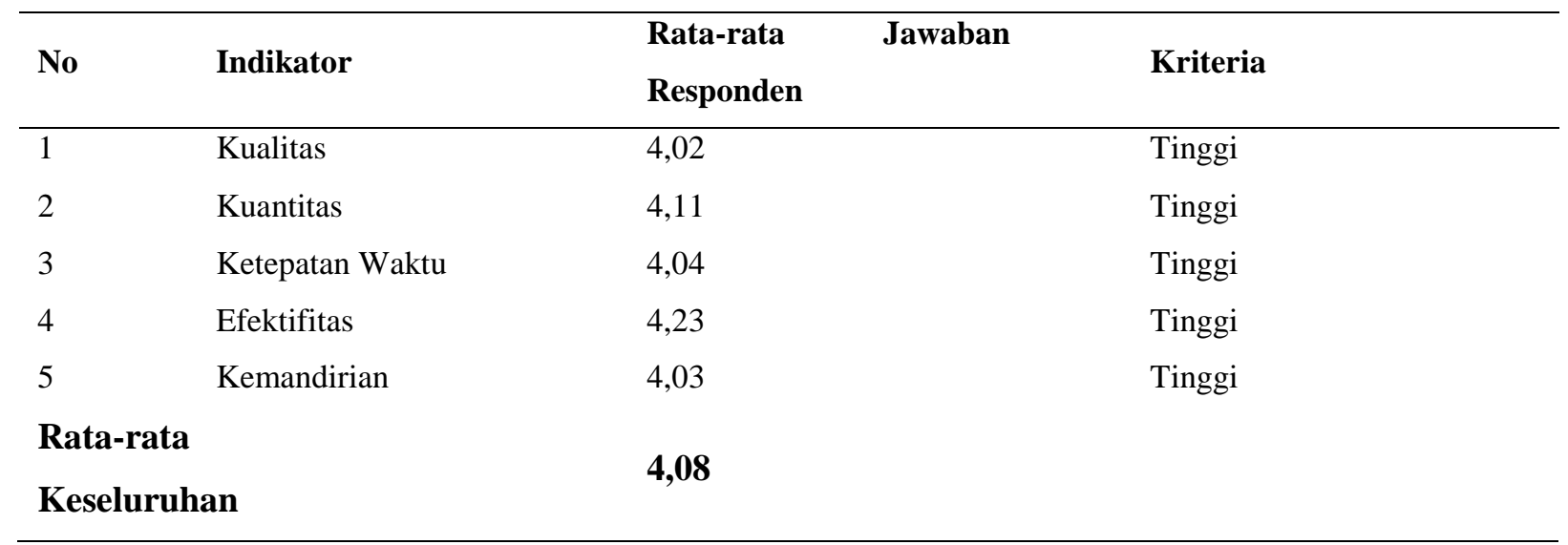

rata-rata jawaban responden setuju sebesar 4,8. Menunjukkan persepsi responden terhadap kinerja SDM mencakup kualitas, kuantitas, ketepatan waktu, efektifitas, dan kemandirian tinggi. 


\section{Tabel 4.4}

Statistik Deskriptif Pelatihan

PDAM Tirta Kencana Kota Samarinda Tahun 2018

\begin{tabular}{cccc}
\hline No & Indikator & $\begin{array}{c}\text { Rata-rata Jawaban } \\
\text { Responden }\end{array}$ & Kriteria \\
\hline 1 & Materi yang dibutuhkan & 3,86 & Tinggi \\
2 & Metode yang digunakan & 3,95 & Tinggi \\
3 & Kemampuan instruktur & 4,15 & Tinggi \\
& pelatihan & & Tinggi \\
4 & Sarana atau prinsip-prinsip & 3,94 & Tinggi \\
& pembelajaran & & Tinggi \\
6 & Peserta pelatihan & 4,04 & \\
& Evaluasi pelatihan & 3,99 & $\mathbf{3 , 9 9}$ \\
\end{tabular}

rata-rata jawaban responden setuju sebesar 3,99. menunjukkan persepsi responden terhadap pelatihan mencakup materi yang dibutuhkan, metode yang digunakan, kemampuan instruktur pelatihan, sarana/prinsip-prinsip pembelajaran, peserta pelatihan, dan evaluasi pelatihan tinggi.

Tabel 4.5

Statistik Deskriptif Kompetensi

PDAM Tirta Kencana Kota Samarinda Tahun 2018

\begin{tabular}{cccc}
\hline No & Indikator & $\begin{array}{c}\text { Rata-rata Jawaban } \\
\text { Responden }\end{array}$ & Kriteria \\
\hline 1 & Motif & 3,84 & Tinggi \\
2 & Sifat & 3,99 & Tinggi \\
3 & Konsep diri & 3,99 & Tinggi \\
4 & Pengetahuan & 3,95 & Tinggi \\
5 & Keterampilan & 4,01 & Tinggi \\
& Rata-rata & $\mathbf{3 , 9 6}$ & \\
& keseluruhan & &
\end{tabular}

rata-rata jawaban responden setuju sebesar 3,96. menunjukkan persepsi responden terhadap pelatihan mencakup: motif, sifat, konsep diri, pengetahuan, dan keterampilan tinggi. 
Tabel 4.6

Statistik Deskriptif Motivasi

PDAM Tirta Kencana Kota Samarinda Tahun 2018

\begin{tabular}{cccc}
\hline No & Indikator & $\begin{array}{c}\text { Rata-rata Jawaban } \\
\text { Responden }\end{array}$ & Kriteria \\
\hline 1 & Kebutuhan fisiologis & 3,99 & Tinggi \\
2 & Kebutuhan rasa aman & 3,81 & Tinggi \\
3 & Kebutuhan sosial & 3,94 & Tinggi \\
4 & Kebutuhan penghargaan & 4,05 & Tinggi \\
5 & Kebutuhan aktualisasi diri & 3,97 & Tinggi \\
& Rata-rata Keseluruhan & $\mathbf{3 , 9 5}$ & \\
\hline
\end{tabular}

rata-rata jawaban responden setuju sebesar 3,95. menunjukkan persepsi responden terhadap motivasi mencakup: kebutuhan fisiologis, rasa aman, sosial, penghargaan, dan aktualisasi diri tinggi

\section{Analisis Data}

a. Uji asumsi klasik

Tabel 4.11

Uji Multikolinearitas

\begin{tabular}{llll}
\hline No & Variabel Bebas & Tolerance & VIF \\
\hline 1 & Pelatihan $\left(\mathrm{X}_{1}\right)$ & 0,874 & 1,144 \\
2 & Kompetensi $\left(\mathrm{X}_{2}\right)$ & 0,710 & 1,408 \\
3 & Motivasi $\left(\mathrm{X}_{3}\right)$ & 0,646 & 1,548
\end{tabular}

toleransi di atas 0,1 dan VIF dibawah 10, maka tidak terjadi multikolinieritas.

\section{Heterodastisitas}

Gambar 4.1 Scatterplot variabel dependen Kinerja SDM (Y1)

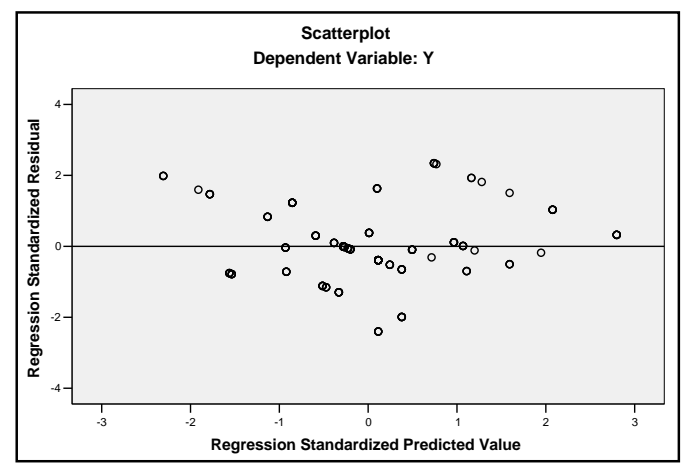




\section{Gambar 4.2 Scatterplot variabel dependen Kompetensi SDM (Y2/X2)}

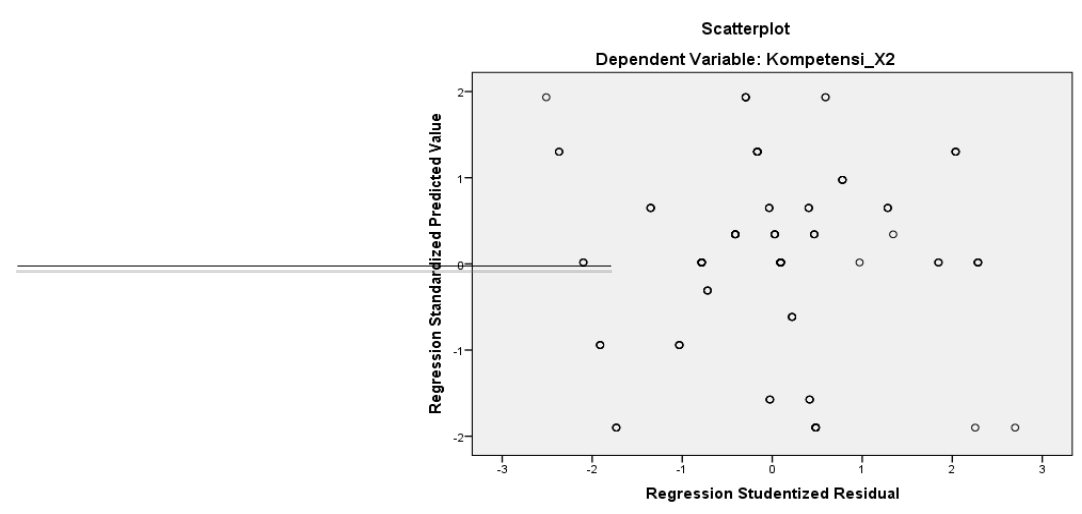

pada Gambar 4.1 variabel dependen kinerja SDM dan 4.2 variabel dependen kompetensi SDM pada sumbu Y titik-titik menyebar secara acak di atas maupun di bawah angka 0. maka tidak terjadi heterodastisitas.

\section{Normalitas}

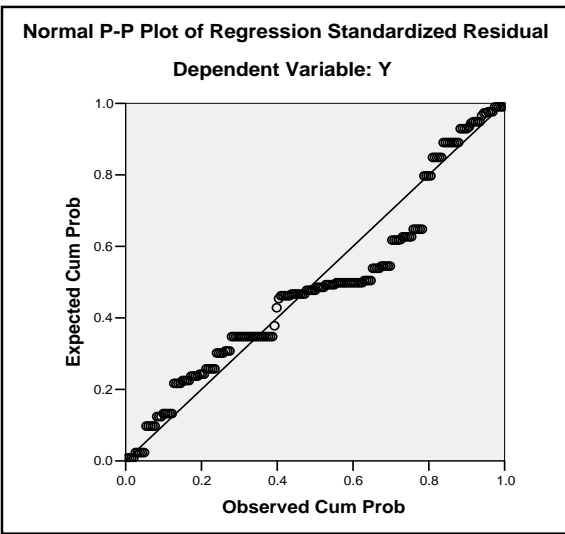

\section{Gambar 4.3 Normal P Plot Kinerja SDM (Y1)}

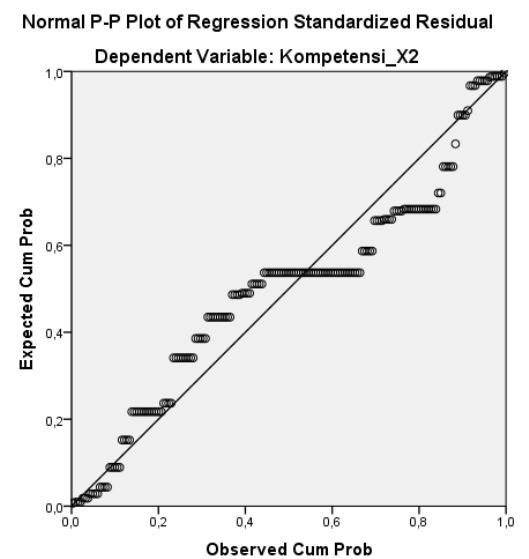

Gambar 4.4 Normal P Plot Kompetensi SDM (Y2/X2) 
titik-titik menyebar di sekitar diagonal menunjukkan berdistribusi normal.

\section{b. Regresi berganda}

Tabel 4.12

Rangkuman Regresi variabel dependen kinerja SDM (Y1)

\begin{tabular}{cccc}
\hline Variabel & Koefisien & t hitung & Signifikansi \\
\hline Konstanta & 0,818 & 3,179 & 0,002 \\
Pelatihan $\left(\mathrm{X}_{1}\right)$ & 0,116 & 2,507 & 0,013 \\
Kompetensi $\left(\mathrm{X}_{2}\right)$ & 0,249 & 4,347 & 0,000 \\
Motivasi $\left(\mathrm{X}_{3}\right)$ & 0,460 & 6,657 & 0,000 \\
R squared & $\mathbf{0 , 4 9 5}$ & F hitung & $\mathbf{= 5 6 , 5 3 5}$ \\
$\mathbf{R}$ & $\mathbf{0 , 7 0 4}$ & Sig. F & $\mathbf{= 0 , 0 0 0}$ \\
\hline
\end{tabular}

$\mathrm{Y} 1=0,818+0,116 \mathrm{X} 1+0,249 \times 2+0,460 \times 3$

Tabel 4.13

Rangkuman Regresi variabel dependen kompetensi (Y2/X2)

\begin{tabular}{llll}
\hline Variabel & Koefisien & t hitung & Signifikansi \\
\hline Konstanta & 3,255 & 12,236 & 0,000 \\
Pelatihan (X1) & 0,176 & 2,655 & 0,009 \\
R squared = & $\mathbf{0 , 0 3 9}$ & F hitung $=$ & $\mathbf{7 , 0 4 9}$ \\
R $=$ & $\mathbf{0 , 1 9 7}$ & Sig. F $=$ & $\mathbf{0 , 0 0 9}$ \\
\hline
\end{tabular}

$\mathrm{Y} 2 / \mathrm{X} 2=3,255+0,176 \mathrm{X} 1$

Uji t

a). Angka df $=n-k(177-4)=173$. Nilai $t$ hitung pelatihan $\left(X_{1}\right) 2,507$ dan $t$ tabel 1,6537 , nilai koefisien Pelatihan $\left(\mathrm{X}_{1}\right)$ 0,116 (positif). Karena nilai $t$ hitung $>t$ tabel, maka $\mathrm{H}_{\mathrm{o}}$ ditolak danH $\mathrm{H}_{\mathrm{a}}$ diterima. Berarti Pelatihan $\left(\mathrm{X}_{1}\right)$ berpengaruh positif terhadap Kinerja SDM $(\mathrm{Y})$. b). Angka df $=\mathrm{n}-\mathrm{k}(177-4)=$ 173. Nilai t hitung kompetensi $\left(X_{2}\right) 4,347$ dan t tabel 1,6537, nilai koefisien variabel Kompetensi $\left(X_{2}\right)$ 0,246 (positif). Karena nilai $\mathrm{t}$ hitung > t tabel, maka disimpulkan bahwa $\mathrm{H}_{\mathrm{o}}$ ditolak dan $\mathrm{H}_{\mathrm{a}}$ diterima. BerartiKompetensi $\left(\mathrm{X}_{2}\right)$ berpengaruh positif terhadap Kinerja SDM $(\mathrm{Y})$. c). Angka df $=\mathrm{n}-\mathrm{k}(177-4)$ $=173$. Nilai $\mathrm{t}$ hitung motivasi $\left(\mathrm{X}_{3}\right)$ 6,657 dan t tabel 1,6537, nilai koefisien Motivasi $\left(\mathrm{X}_{3}\right) 0,460$ (positif). Karena nilai t hitung > t tabel, maka disimpulkan bahwa $\mathrm{H}_{\mathrm{o}}$ ditolak dan $\mathrm{H}_{\mathrm{a}}$ diterima. Berarti motivasi $\left(\mathrm{X}_{3}\right)$ berpengaruh positif terhadap Kinerja SDM $(\mathrm{Y})$. d). Angka df $=\mathrm{n}-\mathrm{k}(177-2)=175$. Nilai t hitung pelatihan $\left(\mathrm{X}_{1}\right)$ 2,655 dan t tabel 1,65361 dan nilai koefisien pelatihan $\left(\mathrm{X}_{1}\right)$ 0,176 
(positif). Karena nilai t hitung > t tabel, maka disimpulkan bahwa $\mathrm{H}_{\mathrm{o}}$ ditolak dan $\mathrm{H}_{\mathrm{a}}$ diterima. Berarti pelatihan $\left(\mathrm{X}_{1}\right)$ berpengaruh positif terhadap variabel kompetensi $\left(\mathrm{X}_{2}\right)$.

Hasil analisis regresi menunjukkan nilai koefisien regresi Motivasi $\left(\mathrm{X}_{3}\right)$, yaitu 0,460 lebih besar daripada Pelatihan $\left(\mathrm{X}_{1}\right)$ dan Kompetensi $\left(\mathrm{X}_{2}\right)$, berarti motivasi merupakan faktor yang mempunyai pengaruh paling besar terhadap kinerja SDM.

\section{Uji Model (Uji F)}

Tabel 4.12 variabel dependen kinerja SDM (Y1) nilai df $1=3$, df $2=172$ didapatkan nilai $F$ hitung sebesar 56,535 dan $\mathrm{F}$ tabel 2,66. Nilai $\mathrm{F}$ hitung > F tabel, berarti pelatihan, kompetensi dan motivasi berpengaruh bersama-sama terhadap variabel kinerja SDM.

Tabel 4.13 variabel dependen Kompetensi SDM (X2/Y2) dapat diketahui nilai df $1=1$, df $2=$ 174 didapatkanNilai F hitung sebesar 7,049 dan F tabel 3,90. Nilai F hitung > F tabel, berartiPelatihan $\left(\mathrm{X}_{1}\right)$ berpengaruh bersama-sama terhadap kinerja SDM melalui variabel intervening Kompetensi $\left(\mathrm{X}_{2}\right)$.

\section{Koefisien Determinasi $\left(\mathbf{R}^{2}\right)$}

Tabel 4.12dan 4.13 nilai koefisien determinasi $\left(\mathrm{R}^{2}\right)$ 0,495. Kinerja SDM (Y) dapat dipengaruhi oleh variabel Pelatihan $\left(\mathrm{X}_{1}\right)$, Kompetensi $\left(\mathrm{X}_{2}\right)$, dan Motivasi $\left(\mathrm{X}_{3}\right)$ sebesar 49,5\%, dan 50,5\% sisanya dipengaruhi oleh faktor lain.

\section{KESIMPULAN}

\section{Kesimpulan}

Kesimpulan dari analisis dan pembahasan pada PDAM TIRTA KENCANA KOTA SAMARINDA: 1). Pelatihan berpengaruh positif terhadap kinerja SDM. 2). Kompetensi berpengaruh positif terhadap kinerja SDM. 3). Motivasi aktualisasi diri berpengaruh positif terhadap kinerja SDM. 4). Pelatihan berpengaruh positif terhadap kinerja SDM melalui kompetensi SDM sebagai variabel intervening. 


\section{DAFTAR PUSTAKA}

Afshan Sultana, dkk, 2012,Impact Of Training On Employee Performance : A Study Of Telecommunication Sector In Pakistan, Interdisciplinary Journal Of Contemporary Ressearch In Business, Vol. 4, No. 6,October.

Aguinis, H., and K. Kraiger. (2009)Benefits of training and development for individuals and teams, organizations, and society. Annual Review of Psychology.

Anwar Prabu Mangkunegara. 2000. Manajemen Sumber Daya Manusia Perusahaan, Bandung: Remaja Rosda Karya.

Arikunto, Suharsimi. 2010. Prosedur Penelitian Suatu Pendekatan Praktek. Jakarta: Rineka Cipta.

Azwar, Saifuddin, 2004. Metode Penelitian, Cetakan V. Yogyakarta: Pustaka Pelajar

Blumberg, M, \& Charles D. Pringle. (1982). The missing opportunities in organizational research: some implications for a theory of work performance. Academy of manajement review.

Boyatzis, R.E., 1982. The Competent Manager: A Model of Effective Performance. New York: John Wiley \& Sons.

Cascio, W.F. 2006. Managing Human Resources - Productivity Quality of Work Life, Profits. McGraw-Hill., United States.

Cushway, Barry, 2002. Human Resource Management. Jakarta: PT. Gramedia.

Dubois, Daid, D."The Executive Guide to Competency-Based PerformanceImprovement", HRD Press Harvest, 1996.

Ghozali, Imam. 2009. "Aplikasi Analisis Multivariate dengan Program SPSS “. Semarang: UNDIP.

Gibson, dkk. 1987. Organisasi : Perilaku, Struktur, Proses. Jakarta: Erlangga.

Gujarati, Damodar. 2003. Ekonometrika Dasar. Jakarta : Erlangga.

Iqbal, Javed. 2012. Employee Motivation In Modern Oreganization: A Review Of 12 Year. Vol 4 No 3. July.

Jackson, schuler, Werner. (2011), Pengelolaan Sumber Daya Manusia, Jakarta: Salemba Empat.

Jagero, Nelson Et al. 2012. Relationship Between On The Job Training and Employee's Performance In Courier. 
Kaymaz, Kurtulus. 2010. The Effect of Job Rotation Practices on Motivation : A research on Managers in the Automotive Organizations. Business and Economics.Vol. 1 No. 3.

Kerlinger. 2006. Asas - Asas Penelitian Behaviour. Edisi 3, Cetakan 7. Yogyakarta: Gadjah Mada University Press.

Kessler, Robin, 2011, Competency-Based Performance Reviews, "the Career Press, Inc., New Jersey.

Kumar, S. A., Poornima, S. C, Abraham, M.K., \& Jayashree, K., 2003. Entrepreneurship development. New Delhi: New Age International (P) Ltd.

Laporan Evaluasi Kinerja Perusahaan Daerah Air Minum Tirta Kencana Kota Samarinda, 2017.

Luthans, Fred, 2005. Perilaku Organisasi.Yogyakarta: Andi

Hanafi, Mamduh M., 2003, Manajemen. Yogyakarta: UPPAMP YKPN.

Martoyo, Susilo, 2000. Manajemen Sumber Daya Manusia. Yogyakarta: BPFE.

Maslow, Abraham H., (1954), Motivation And Personality, Harper \& Row Publiser, New York.

Mathis, Robert L., John H. Jackson. 2002. Manajemen Sumber Daya Manusia, Edisi Pertama Salemba Empat, Jakarta.

Mills, Roger W. 2006. The Competencies Pocketbook, management pocketbook- ltd.

Moeheriono. 2009. Pengukuran Kinerja Berbasis Kompetensi. Bogor: Ghalia Indonesia.

Nazir, Moh. 2005. Metode Penelitian. Jakarta: Ghalia Indonesia.

Nawab er al., 2011. Effect of Motivation on Employees Performance. Interdisciplinary Journal of Contemporary Research In Business. Vol. 3 (3), 1209-1216.

Nurlaila, 2010. Manajemen Sumber Daya Manusia. Ternate: Lep Khair.

Palan, R. 2007.Competency Management: Teknis Mengimplementasikan Manajemen SDM Berbasis Kompetensi untuk Meningkatkan Daya Saing, Organisasi. PPM.Jakarta.

Prihadi, Syaiful F., 2004. Assesment Centre: Identifikasi, pengukuran dan Pengembangan Kompetensi. Jakarta: Gramedia Pustaka Utama. 
Robbins, Stephen P. 2006. Perilaku Organisasi. Edisi kesepuluh. Jakarta: PT Indeks Kelompok Gramedia.

Shah, James Y. \& Wendi L Gardner. 2008. Handbook of Motivation Science. New York: Guilford.

Spencer, Lyle \& Signe M. Spencer. 1993. Competence at Work, Models For Superior Performance. Canada: John Wiley \& Sons, Inc.

Sri Lastanti, Hexana. 2005. Tinjauan Terhadap Kompetensi dan Independensi Akuntan Publik : Refleksi Atas Skandal Keuangan. Media Riset Akuntansi, Auditing dan Informasi Vol. 5 No. 1 April 2005.

Sugiyono, 2013. Metode Penelitian Kuantitatif dan Kualitatif. Bandung: CV Alfabeta.

Seukardi, 2013. Metode Penelitian Pendidikan Kompetensi dan Prakteknya. Jakarta: Bumi Aksara.

Veithzal Rivai, 2004. Manajemen Sumber Daya Manusia untuk Perusahaan dari Teori ke Praktik, Jakarta: PT Raja Grafindo Persada.

Vellayudhan, M. 2011. Competency Mapping of the Employees - A Study. International Conference on Information Communication and Management (pp. 228-231). Singapore: IACSIT Press.

Vroom V. 1964. Work and Motivation. New York: Wiley.

Warsito, Bambang, 2008, Manajemen Sumber Daya Manusia, Malang: Surya Pena Gemilang.

Werner, Jhon M., \& De Simone, Randy L. 2009. Human Resources Development, 5 th Edition. South-Western Cengage Learning: Mason.

\section{Jurnal/Skripsi/Tesis:}

Abdul Hameed Aamer Waheed, 2011. Employee Development and It's Affect on Employee Performance A Conceptual Framework. Employee is a key element of the organization. International Journal of Business and Social Science.

Amin, A, Rashid Saeed, M., \& Lodhi, R. N. (2013).The Impact of Employees Training On the Job Performance in Education Sector Of Pakistan.Middle-East Journal of Scientific Research, 17(9), 1273-1278.

Chapman, C. 1999.Project Risk Analysis and Management PRAM the Generic Process.International Journal of Project Magement, Vol.15. No. 5.

Brum, Scott, 2007. Training Have on Employee Commitment and Employee Turnover?".

Dermawan AANB, Sudibja IGA. Utama,IWM. (2012). "Pengaruh motivasi, lingkungan Kerja, kompetensi dan kompensasi terhadap kepuasan Kerja dan Kinerja Pegawai 
di Lingkungan kantor DPU Propinsi Bali.” Jurnal Manajemen, Strategi Bisnis, dan Kewirausahaan, Vol. 6 (2), pp. 173-184.

Elaine Tjeng, et. al. 2013.Pengaruh ProgramPelatihlan dan Pengmbangan Terhadap Kinerja Karyawan Pada PT. Bank Central Asia, TBK.

Heri Sapari Kahpi, dkk (2017) berjudul "Pengaruh pelatihan dan motivasi berprestasi terhadap kinerja pegawai dengan kompetensi sebagai variabel intervening" (Studi Empiris Pada Pegawai Perusahaan Daerah Air Minum Kabupaten Lebak.Jurnal Riset Bisnis dan Manajemen Tirtayasa.

Ida Ayu Brahmasari \& Agus Suprayetno 2008. Pengaruh Motivasi Kerja, Kepemimpinan dan Budaya Organisasi Terhadap Kepuasan Kerja Karyawan serta Dampaknya pada Kinerja Perusahaan.

Mohd Noor, K. B., \& Dola K. 2009.Job Competencies for Malaysian Managers in Higher Education Institution. Asian Journal of Management and Humanity Sciences, Vol. 4, No. 4, pp. 226-240.

Niazi.Abdus Sattar. (2011) Training and Development Strategy and Its Role in Organizational Performance.

Ni Putu Darmayanti, dkk (2014) berjudul "Pengaruh kompetensi intelektual dan motivasi berprestasi terhadap kinerja pegawai pada perusahaan daerah air minum di kabupaten Gianyar.

Subari s \& H. Riyady. 2015. Influence of Training, Competence and Motivation on Employee performance, Moderated By internal comunications.

Widyasmoko, A. 2011.Pengaruh Pengawasan dan Kompetensi Pegawai terhadap Kinerja Pegawai pda Dinas Pertanian dan Kehutanan Kabupaten Bintan Provinsi Riau. 